\title{
Female Sex and Right-Sided Tumor Location Are Poor Prognostic Factors for Patients With Stage III Colon Cancer After a Curative Resection
}

\author{
Jung Ho Park ${ }^{1}$, Hyoung-Chul Park ${ }^{1,2}$, Sung Chan Park², Jae Hwan Oh², Duck-Woo Kim³, Sung-Bum Kang ${ }^{3}$, \\ Seung Chul Heo ${ }^{4}$, Min Jung Kim²,5, Ji Won Park ${ }^{5}$, Seung-Yong Jeong ${ }^{5}$, Kyu Joo Park ${ }^{5}$; for the Seoul \\ Colorectal Group (SECOG) \\ ${ }^{1}$ Department of Surgery, Hallym University Sacred Heart Hospital, Anyang; ${ }^{2}$ Center for Colorectal Cancer, Research Institute and Hospital, \\ National Cancer Center, Goyang; ${ }^{3}$ Department of Surgery, Seoul National University Bundang Hospital, Seongnam; ${ }^{4}$ Department of Surgery, \\ Seoul Metropolitan Government-Seoul National University Boramae Medical Center, Seoul; ${ }^{5}$ Department of Surgery, Seoul National \\ University College of Medicine, Seoul, Korea
}

Purpose: Stage-IIIC colon cancer is an advanced disease; however, its oncologic outcomes and prognostic factors remain unclear. In this study, we aimed to determine the predictors of disease-free survival (DFS) in patients with stage-IIIC colon cancer.

Methods: From a multicenter database, we retrospectively enrolled 611 patients (355 men and 256 women) who had undergone a potentially curative resection for a stage-IIIC colon adenocarcinoma between 2003 and 2011. The primary endpoint was the 5-year DFS.

Results: The median age was 62 years; 213 and 398 patients had right-sided colon cancer (RCC) and left-sided colon cancer (LCC), respectively. The 5-year DFS in all patients was 52.0\%; median follow-up time was 35 months (range, 1-134 months). A multivariate Cox regression revealed that female sex (hazard ratio [HR], 1.50; 95\% confidence interval [CI], 1.19-1.90; $\mathrm{P}<0.01$ ), right-sided tumor location (HR, 1.65; 95\% CI, 1.29-2.11; $\mathrm{P}<0.01$ ), lymphatic invasion (HR, 1.52; 95\% CI, 1.08-2.15; P < 0.01) and a high $(\geq 0.4)$ metastatic lymph node ratio (HR, 3.72; 95\% CI, 2.63-5.24; P < 0.01) were independent predictors of worse 5-year DFS. Female patients with RCC were 1.79 fold more likely to experience recurrence than male patients with LCC.

Conclusion: Female sex and right-sided tumor location are associated with higher tumor recurrence rates in patients with stage-IIIC colon cancers. Aggressive treatment and close surveillance should be planned for patients in these groups.

Keywords: Colonic neoplasms; Ascending colon; Descending colon; Prognosis; Recurrence

\section{INTRODUCTION}

Colorectal cancer is one of the most common cancers worldwide.

Received: July 13,2018 • Accepted: October 29, 2018

Correspondence to: Hyoung-Chul Park, M.D.

Center for Colorectal Cancer, Research Institute and Hospital, National

Cancer Center, 323 Ilsan-ro, Ilsandong-gu, Goyang 10408, Korea

Tel: +82-31-920-1608, Fax: +82-31-920-1148

E-mail: greatpa1@ncc.re.kr

ORCID code: https://orcid.org/0000-0002-1369-8757

(C) 2018 The Korean Society of Coloproctology

This is an open-access article distributed under the terms of the Creative Commons Attribution NonCommercial License (http://creativecommons.org/licenses/by-nc/4.0) which permits unrestricted noncommercial use, distribution, and reproduction in any medium, provided the original work is properly cited.
In 2014, it was the third most commonly diagnosed cancer in Korea and the most commonly diagnosed cancer among women 65 years of age and older [1]. The mainstay treatment for patients with colon cancer is surgical resection with en bloc removal of the regional lymph nodes.

The prognosis for patients with colon cancer has improved over the past several decades owing in part to early detection [2]. Despite advances in surgical techniques and adjunctive chemotherapy, patients with stage-IIIC colon cancer have poor survival rates; the 5-year survival rate is about $28.0 \%$ [3]. Because few studies investigating the prognostic factors in patients with stage-IIIC colon cancer have been reported in the literature, the aim of this study was to identify the clinicopathologic factors that influence the 
5-year disease-free survival (DFS) in patients with this particular disease stage of colon cancer.

\section{METHODS}

\section{Patients}

Between 2003 and 2011, 611 patients with stage IIIC colon cancers were sequentially enrolled from 5 referral centers in Korea. All patients had been histologically diagnosed with an adenocarcinoma of the colon and had undergone potentially curative surgery. An adjuvant chemotherapy based on 5-fluorouracil was given after surgery. Patients with histology other than an adenocarcinoma; patients with rectal cancer, hereditary cancer, synchronous colon cancer, metachronous cancer or other primary cancers; patients with less than 12 lymph nodes evaluated; patients who did not receive chemotherapy and patients who died within 30 days after surgery were excluded. All data on clinical and pathological features were reviewed retrospectively. This study was approved by the Hallym University Institutional Review Board (12-I048). The Institutional Review Board agreed to waive the requirement to obtain informed written consent from each patient.

Right-sided colon cancer (RCC) was defined as a tumor arising from the appendix, cecum, ascending colon, hepatic flexure, and proximal two-thirds of the transverse colon. Tumors arising from the distal third of the transverse colon, splenic flexure, descending colon, rectosigmoid junction and sigmoid colon were defined as left-sided colon cancers (LCCs).

Specimens were examined by pathologists at each of the five centers. The TNM stage was defined according to the American Joint Committee on Cancer (7th edition) [3]. More than 12 lymph nodes were examined for each specimen. The lymph node ratio (LNR) was defined as the number of metastatic lymph nodes divided by the number of retrieved lymph nodes. DFS was defined as the time interval between the date of surgery and the date of the detection of recurrence, last follow-up, or death. Adjuvant chemotherapy with a 5-fluorouracil-based regimen was administrated. Patients' demographics and pathological and oncologic outcomes were compared between the RCC and the LCC groups.

\section{Statistical analyses}

All statistical analyses were performed using the IBM SPSS Statistics ver. 24.0 (IBM Co., Armonk, NY, USA). Categorical variables were analyzed using the chi-square test. Analyses of continuous variables were performed using the Student $t$-test. The DFS was analyzed using the Kaplan-Meier method, and comparisons were performed using the log-rank test. The Cox proportional-hazards model was used for multivariate analyses to identify the prognostic factors for 5-year DFS. Statistical tests were two-sided, and a Pvalue less than 0.05 was considered statistically significant.

\section{RESULTS}

\section{Patients' characteristics}

The clinicopathologic data of 611 patients are summarized in Table 1. The median age of the patients was 62 years (range, 17-93 years), and 355 patients (58.1\%) were male. Of the 611 patients, 398 (65.1\%) had been diagnosed with LCC. The mean tumor size

Table 1. Clinicopathologic factors of the 611 stage-IIIC colon cancer patients

\begin{tabular}{|c|c|}
\hline Factor & Value \\
\hline \multicolumn{2}{|l|}{ Age (yr) } \\
\hline$\leq 50$ & $132(21.6)$ \\
\hline $51-70$ & $357(58.4)$ \\
\hline$\geq 71$ & $122(20.0)$ \\
\hline \multicolumn{2}{|l|}{ Sex } \\
\hline Male & $355(58.1)$ \\
\hline Female & $256(41.9)$ \\
\hline \multicolumn{2}{|l|}{ Location } \\
\hline Right & $213(34.9)$ \\
\hline Left & $398(65.1)$ \\
\hline Tumor size (cm) & $6.24 \pm 2.00$ \\
\hline \multicolumn{2}{|l|}{ T stage } \\
\hline T3 & $268(43.9)$ \\
\hline $\mathrm{T} 4 \mathrm{a}$ & $83(13.6)$ \\
\hline $\mathrm{T} 4 \mathrm{~b}$ & $260(42.6)$ \\
\hline Mean total lymph nodes & 32.5 \\
\hline \multicolumn{2}{|l|}{ N stage } \\
\hline N1 & $126(20.6)$ \\
\hline $\mathrm{N} 2 \mathrm{a}$ & $82(13.4)$ \\
\hline $\mathrm{N} 2 \mathrm{~b}$ & $403(66.0)$ \\
\hline \multicolumn{2}{|l|}{ Lymph node ratio } \\
\hline$\leq 0.19$ & $175(28.6)$ \\
\hline $0.2-0.39$ & $269(44.0)$ \\
\hline$\geq 0.4$ & $167(27.3)$ \\
\hline \multicolumn{2}{|l|}{ Lymphatic invasion } \\
\hline Yes & 509 (83.3) \\
\hline No & $102(16.7)$ \\
\hline \multicolumn{2}{|l|}{ Vascular invasion } \\
\hline Yes & $268(43.9)$ \\
\hline No & $343(56.1)$ \\
\hline \multicolumn{2}{|l|}{ Perineural invasion } \\
\hline Yes & $289(47.2)$ \\
\hline No & $322(52.8)$ \\
\hline
\end{tabular}

Values are presented as number (\%) or mean \pm standard deviation unless otherwise indicated. 
Table 2. Univariate Cox-proportional regression analysis of 5-year disease-free survival

\begin{tabular}{|c|c|c|c|}
\hline Variable & $\mathrm{HR}$ & $95 \% \mathrm{Cl}$ & P-value \\
\hline Age (yr) & & & 0.11 \\
\hline$\leq 50$ & Reference & & \\
\hline $51-70$ & 0.88 & $0.66-1.17$ & \\
\hline$\geq 71$ & 1.20 & $0.85-1.70$ & \\
\hline Sex & & & $<0.01$ \\
\hline Male & Reference & & \\
\hline Female & 1.39 & $1.10-1.76$ & \\
\hline Location & & & 0.05 \\
\hline Left & Reference & & \\
\hline Right & 1.27 & $1.00-1.61$ & \\
\hline Tumor size (cm) & 1.04 & $0.98-1.10$ & 0.17 \\
\hline T category & & & 0.22 \\
\hline T3 & Reference & & \\
\hline T4a & 0.73 & $0.49-1.07$ & \\
\hline $\mathrm{T} 4 \mathrm{~b}$ & 0.87 & $0.68-1.12$ & \\
\hline $\mathrm{N}$ category & & & $<0.01$ \\
\hline N1 & Reference & & \\
\hline $\mathrm{N} 2 \mathrm{a}$ & 2.17 & $1.39-3.40$ & \\
\hline $\mathrm{N} 2 \mathrm{~b}$ & 2.49 & $1.75-3.56$ & \\
\hline Lymph node ratio & & & $<0.01$ \\
\hline$\leq 0.19$ & Reference & & \\
\hline $0.2-0.39$ & 1.86 & $1.37-2.53$ & \\
\hline$\geq 0.4$ & 2.91 & $2.11-4.00$ & \\
\hline Lymphatic invasion & & & 0.02 \\
\hline Absent & Reference & & \\
\hline Present & 1.47 & $1.04-2.06$ & \\
\hline Vascular invasion & & & 0.99 \\
\hline Absent & Reference & & \\
\hline Present & 1.00 & $0.79-1.27$ & \\
\hline Perineural invasion & & & 0.07 \\
\hline Absent & Reference & & \\
\hline Present & 1.24 & $0.98-1.57$ & \\
\hline
\end{tabular}

$\mathrm{HR}$, hazard ratio; $\mathrm{Cl}$, confidence interval.

was $6.24 \mathrm{~cm}$, the mean number of retrieved lymph nodes was 32.5 and the LNR was 0.31 .

\section{Analysis of prognostic factors for survival}

The median overall follow-up period was 35 months (range, 1-134 months). The univariate analysis showed that female sex, RCC, N2b category, LNR $\geq 0.4$, and lymphatic invasion were predictors of poor DFS (Table 2). The multivariate Cox regression analysis revealed that female sex, RCC, LNR $\geq 0.4$ and lymphatic
Table 3. Multivariate Cox-proportional regression analysis of 5-year disease free survival

\begin{tabular}{lccc}
\hline Variable & HR & $95 \% \mathrm{Cl}$ & P-value \\
\hline Sex & & & $<0.01$ \\
Male & Reference & & \\
Female & 1.50 & $1.19-1.90$ & $<0.01$ \\
Location & & & \\
Left & Reference & & \\
Right & 1.65 & $1.29-2.11$ & \\
LNR & & & \\
$\leq 0.19$ & Reference & & \\
$0.2-0.39$ & 2.12 & $1.53-2.93$ & 0.02 \\
$\geq 0.4$ & 3.72 & $2.63-5.24$ & \\
Lymphatic invasion & & & \\
Absent & Reference & & \\
Present & 1.52 & $1.08-2.15$ & \\
\hline
\end{tabular}

HR, hazard ratio; $\mathrm{Cl}$, confidence interval; LNR, lymph node ratio.

invasion were associated with poor 5-year DFS (Table 3).

The 5-year DFSs were poorer for female sex versus male sex $(45.5 \% \pm 3.3 \%$ vs. $56.8 \% \pm 2.8 \%$, respectively), for patients with RCC than for those with LCC $(47.2 \% \pm 3.6 \%$ vs. $54.7 \% \pm 2.7 \%$, respectively) and for patients with lymphatic invasion versus those without $(49.9 \% \pm 2.4 \%$ vs. $63.3 \pm 4.9 \%)$. The 5 -year DFS rates were $68.9 \% \pm 3.7 \%$ in the LNR $\leq 0.19$ group, $50.7 \% \pm 3.2 \%$ in the LNR $=0.2-0.39$ group, and $35.4 \% \pm 4.0 \%$ in the LNR $\geq 0.4$ group (Fig. 1).

\section{Additional analysis of the role of tumor location}

As shown in Fig. 2, category T3N2b diseases were more prevalent in patients with LCC than in those with RCC ( $52 \%$ vs. $29 \%$, respectively). The reverse was true for T4 tumors. Compared to patients with LCC, those with RCC had tumors with a more advanced T stage (T4: $71.4 \%$ vs. $48.0 \%, \mathrm{P}<0.01$ ), a larger number of resected lymph nodes (mean \pm standard deviation: $35.95 \pm 16.09$ vs. $30.67 \pm 14.28, \mathrm{P}<0.01$ ), and a greater frequency of lymphatic invasion $(85.9 \%$ vs. $83.7 \%, \mathrm{P}<0.01)$. However, patients with LCC had more advanced $\mathrm{N}$ stage (N2: $84.1 \%$ vs. $71.2 \%, \mathrm{P}<0.01)$ and greater LNRs ( $\geq 0.4: 32.7 \%$ vs. $17.4 \%, \mathrm{P}<0.01)$.

Female patients with RCC were 1.79 fold more likely to experience recurrence than male patients with LCC (hazard ratio [HR], 1.79; 95\% confidence interval [CI], 1.27-2.51, P $<0.01$ ). No significant differences between the LCC and the RCC groups with respect to mean age, sex, tumor size, and number of metastatic lymph nodes were noted.

\section{DISCUSSION}

In this retrospective study, data on 611 patients with stage-IIIC 

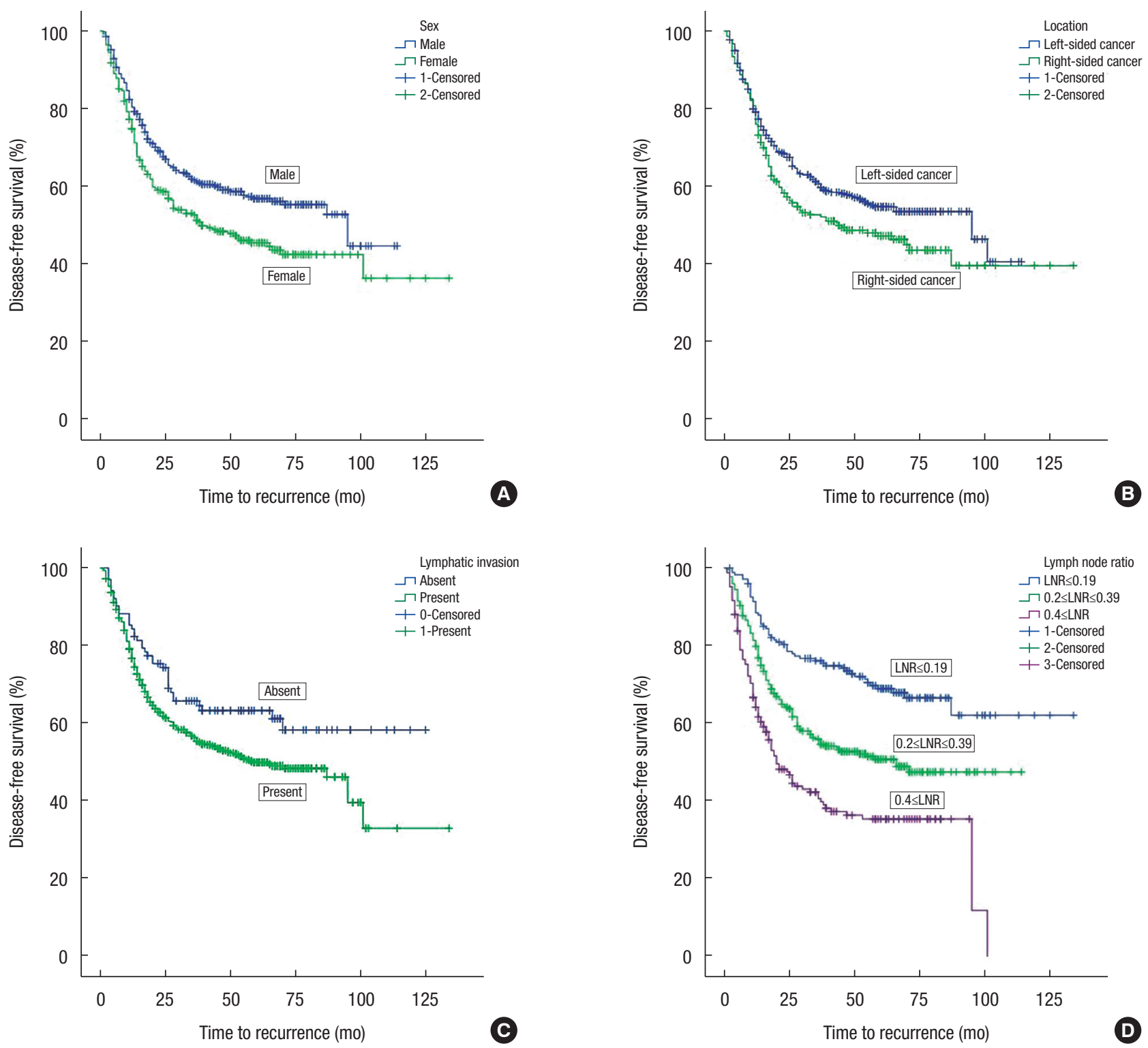

Fig. 1. Kaplan-Meyer survival curves for patients with stage-IIIC colon cancer. Disease-free survival was poor in female patients (A), patients with right-sided colon cancers (B), patients with lymphatic invasion (C), and patients with a high lymph node ratio (D).

colon cancer were extracted from a multicenter database. On multivariate analysis, we demonstrated that female sex, rightsided tumor location, lymphatic invasion and high LNR were poor prognostic factors for 5-year DFS.

It is well established that lymph node metastasis is related to adverse outcomes following a colon cancer resection. Conventionally, lymph node staging of colon cancer is based on the American Joint Committee on Cancer N category. However, several studies have suggested that the LNR could substitute for the $\mathrm{N}$ category [4-6]. Our data revealed a strong relationship between LNR and 5 -year DFS. The LNR $\geq 0.2$ and the LNR $\geq 0.4$ subgroups were associated with 2.13 fold and 3.53 fold increases in the HR, re- spectively.

There is an ongoing debate regarding the differences in survival rates between patients with RCC and those with LCC [7]. Overall, the oncologic outcome of patients with RCC is inferior to that of patient with LCC, but this trend varies depending on the stage [8]. In a study by Meguid et al. [9], patients with stage-III RCC exhibited worse 5-year overall survival than their counterparts with LCC, as did those with stage-IV RCC. In contrast, patients with stage-II RCC showed better survival rates than their LCC counterparts. Two successive studies by Weiss et al. $[10,11]$ and studies performed in Asian countries [12-14] came to similar conclusions. Taken together, for early stage disease, the survival of pa- 


\section{Coloproctology Jung to park calal}
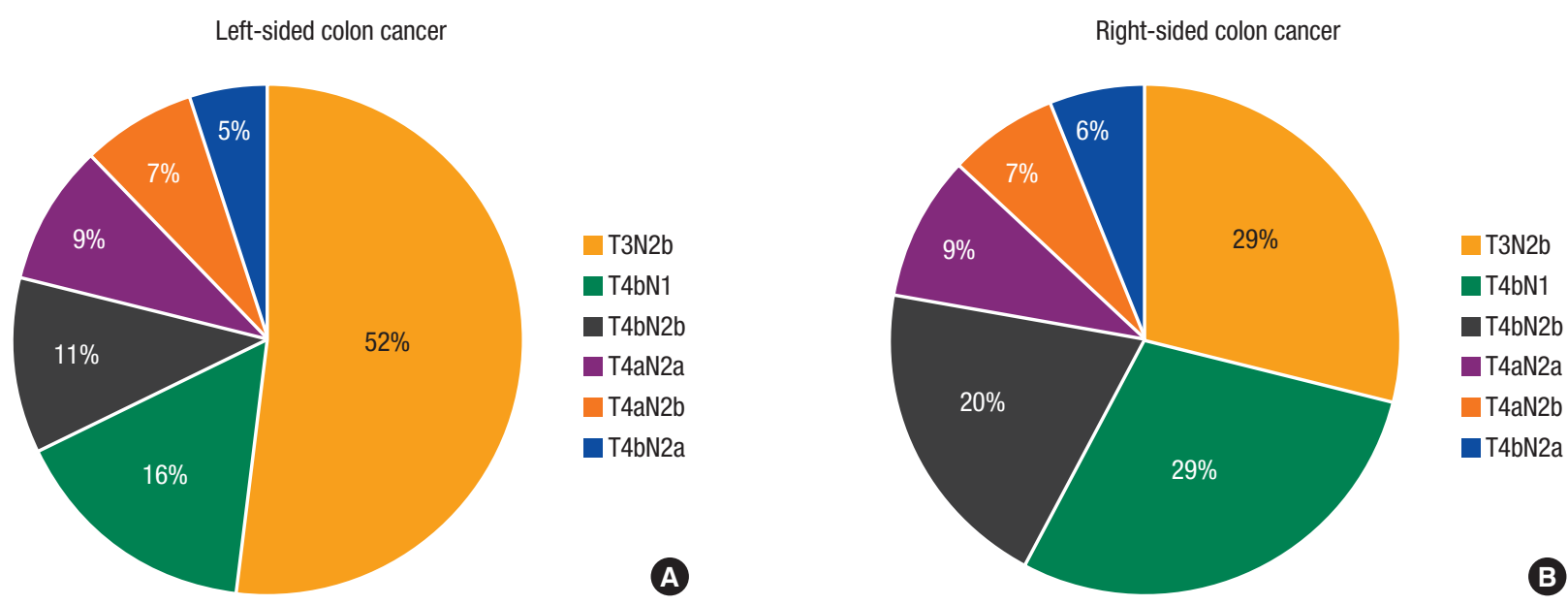

Fig. 2. The different distributions of $\mathrm{T}$ and $\mathrm{N}$ categories in patients with left-sided colon cancer (LCC) (A) and right-sided colon cancer (RCC) (B). (A) T3N2b disease was more common among LCCs. (B) T4 category diseases were more common among RCCs.

tients with RCC is equal to or better than that of patients with LCC, but it becomes poorer as the disease progresses.

The difference between RCC and LCC is attributable to tumor biology. Many studies have reported biologic differences of RCC and LCC. Microsatellite instability (MSI) positive status is common in RCC, and $20 \%-25 \%$ of patients with stage-II RCC are shown to be MSI positive. MSI-positive status is less than $15 \%$ for stage-III RCC and even lower for stage-IV disease. MSI is related to lower stage RCC and is a favorable predictor of survival [10, 11]. Other than MSI status, KRAS and BRAF expressions are also associated with RCC while NRAS mutation and chromosome instability are more common in patients with LCC [15].

Another potential cause of poor outcome in the patients with LCC may be fewer lymph node dissections [16]. The surgical extent for a right hemicolectomy has been well standardized to be from the terminal ileum to half of the transverse colon [17]. However, the extent of lymph node dissection in a left hemicolectomy varies $[16,18]$. Patients with LCC are associated with fewer dissected lymph nodes and a high LNR. Therefore, the standardized techniques of central vascular ligation and total mesocolic excision should be strictly observed in a left hemicolectomy. In the treatment of patients with RCC, incomplete tumor removal in the retroperitoneal resection margin could be a source of recurrence. Therefore, achieving an adequate circumferential resection margin and a complete mesocolic excision with proper dissection plane for patients with RCC is important.

This study has some inherent limitations. First, it is based on a retrospective multicenter database; hence, significant selection bias may exist. Data in this study represent uniform Korean populations; hence, the result would be different from those of previous studies using the Surveillance, Epidemiology and End Results databases. Second, the recurrence patterns of RCC and LCC were not analyzed due to loss during follow-up and insufficient data. Classifying the recurrence pattern in patients with stage-IIIC co- lon cancer is important for guiding treatment. Third, some important treatment-related factors were not considered. Combined resections of adjacent organ structures, such as pancreaticoduodenectomy in patients with right colon cancer with duodenal invasion, were performed in some cases. Pathologic data regarding tumor grade, MSI status, and circumferential resection margin were not available. Chemotherapeutic regimens, doses, treatment durations, and treatment failure rates were also not available. The low socioeconomic status of elderly female patients may have led to poor compliance and adverse outcome.

Despite these limitations, our study is the first to analyze patients with stage-IIIC colon cancer separately, and it produced some important findings. We confirmed that the survival of patients with stage-IIIC RCC is inferior to that of their LCC counterparts. We also found that female sex is another factor for poor prognosis for patients with stage-IIIC colon cancer. When combined, these two clinical factors could be strong predictors of poor outcome.

In conclusion, stage-IIIC colon cancer produces poor oncologic outcomes when occurring in female patients, when it is rightsided, and when the LNR is high. Therefore, a reasonable approach would be to plan more aggressive treatments for female patients with RCC; close surveillance for disease recurrence is also desirable in this group. Further clinical and genetic studies are required to elucidate the mechanisms underlying our findings and to confirm those findings in a large-scale setting.

\section{CONFLICT OF INTEREST}

No potential conflict of interest relevant to this article was reported.

\section{REFERENCES}

1. Jung KW, Won YJ, Oh CM, Kong HJ, Lee DH, Lee KH, et al. Can- 
cer statistics in Korea: incidence, mortality, survival, and prevalence in 2014. Cancer Res Treat 2017;49:292-305.

2. Park HC, Shin A, Kim BW, Jung KW, Won YJ, Oh JH, et al. Data on the characteristics and the survival of korean patients with colorectal cancer from the Korea central cancer registry. Ann Coloproctol 2013;29:144-9.

3. Jessup JM, Goldberg RM, Asare EA, Benson AB III, Brierley JD, Chang GJ, et al. Colon and rectum. In: Edge SB, Byrd DR, Compton CC, Fritz AG, Greene FL, Trotti A, editors. AJCC cancer staging manual. 7th ed. New York: Springer; 2010. p. 143-64.

4. Park IJ, Choi GS, Jun SH. Nodal stage of stage III colon cancer: the impact of metastatic lymph node ratio. J Surg Oncol 2009;100: 240-3.

5. Sabbagh C, Mauvais F, Cosse C, Rebibo L, Joly JP, Dromer D, et al. A lymph node ratio of $10 \%$ is predictive of survival in stage III colon cancer: a French regional study. Int Surg 2014;99:344-53.

6. Sugimoto K, Sakamoto K, Tomiki Y, Goto M, Kotake K, Sugihara K. Proposal of new classification for stage III colon cancer based on the lymph node ratio: analysis of 4,172 patients from multi-institutional database in Japan. Ann Surg Oncol 2015;22:528-34.

7. Powell AG, Wallace R, McKee RF, Anderson JH, Going JJ, Edwards J, et al. The relationship between tumour site, clinicopathological characteristics and cancer-specific survival in patients undergoing surgery for colorectal cancer. Colorectal Dis 2012;14: 1493-9.

8. Benedix F, Kube R, Meyer F, Schmidt U, Gastinger I, Lippert H, et al. Comparison of 17,641 patients with right- and left-sided colon cancer: differences in epidemiology, perioperative course, histology, and survival. Dis Colon Rectum 2010;53:57-64.

9. Meguid RA, Slidell MB, Wolfgang CL, Chang DC, Ahuja N. Is there a difference in survival between right- versus left-sided colon cancers? Ann Surg Oncol 2008;15:2388-94.

10. Weiss JM, Pfau PR, O’Connor ES, King J, LoConte N, Kennedy G, et al. Mortality by stage for right- versus left-sided colon cancer: analysis of surveillance, epidemiology, and end results--Medicare data. J Clin Oncol 2011;29:4401-9.

11. Weiss JM, Schumacher J, Allen GO, Neuman H, Lange EO, Loconte NK, et al. Adjuvant chemotherapy for stage II right-sided and left-sided colon cancer: analysis of SEER-medicare data. Ann Surg Oncol 2014;21:1781-91.

12. Moritani K, Hasegawa H, Okabayashi K, Ishii Y, Endo T, Kitagawa $Y$. Difference in the recurrence rate between right- and leftsided colon cancer: a 17-year experience at a single institution. Surg Today 2014;44:1685-91.

13. Huang CW, Tsai HL, Huang MY, Huang CM, Yeh YS, Ma CJ, et al. Different clinicopathologic features and favorable outcomes of patients with stage III left-sided colon cancer. World J Surg Oncol 2015;13:257.

14. Lim DR, Kuk JK, Kim T, Shin EJ. Comparison of oncological outcomes of right-sided colon cancer versus left-sided colon cancer after curative resection: which side is better outcome? Medicine (Baltimore) 2017;96:e8241.

15. Shen H, Yang J, Huang Q, Jiang MJ, Tan YN, Fu JF, et al. Different treatment strategies and molecular features between right-sided and left-sided colon cancers. World J Gastroenterol 2015;21:64708.

16. Guan X, Chen W, Liu Z, Jiang Z, Hu H, Zhao Z, et al. Whether regional lymph nodes evaluation should be equally required for both right and left colon cancer. Oncotarget 2016;7:59945-56.

17. Hohenberger W, Weber K, Matzel K, Papadopoulos T, Merkel S. Standardized surgery for colonic cancer: complete mesocolic excision and central ligation--technical notes and outcome. Colorectal Dis 2009;11:354-64.

18. West NP, Hohenberger W, Weber K, Perrakis A, Finan PJ, Quirke P. Complete mesocolic excision with central vascular ligation produces an oncologically superior specimen compared with standard surgery for carcinoma of the colon. J Clin Oncol 2010; 28:272-8 